\title{
CONFIABILIDADE, COERÊNCIA E METAINCOERÊNCIA (continuação e fim)
}

\section{RELIABILITY, COHERENCE AND METAINCOHERENCE (continuation and conclusion)}

\author{
Emerson Carlos Valcarenghi*
}

\begin{abstract}
RESUMO - Este artigo discute casos de metaincoerência doxástica em que a crença metaincoerente é ativa na geração da crença-alvo. Esses casos, que são casos de injustificação doxástica, provam a necessidade de complementarmos as propostas confiabilistas de justificação. É essa complementação que tentaremos fazer aqui, mas sem recorrer a qualquer cláusula do tipo antisolapamento da justificação.

PALAVRAS-CHAVE - Justificação doxástica. Confiabilismo. metaincoerência.

ABSTRACT - This essay discusses cases of doxastic metaincoherence in which the metaincoherence belief is active in targetbelief generation. Those cases, which are cases of doxastic nonjustification, show the need to complement reliabilist proposals of justification. It is what we try to do here, but not recurring to any undermining type clause of justification.

KEYWORDS - Doxastic justification. Reliabilism. Metaincoherence.
\end{abstract}

\section{IV}

(JDNDI), (JDDI) e (JDNI) constituem o conjunto de propostas que faremos uso para lidar com casos em que a crença metaincoerente é ativa na geração da crença-alvo. Comecemos com o seguinte:

* Professor do Mestrado em Ética e Epistemologia da UFPI. <ecvalcarenghi@yahoo.com.br>.

\begin{tabular}{|l|l|l|l|l|l|}
\hline Veritas & Porto Alegre & v. 56 & n. 2 & maio/ago. 2011 & p. 121-140 \\
\hline
\end{tabular}


Caso-11: Suponhamos que, através da execução de $\pi, \mathrm{S}$ forma, em $\mathrm{t}, \mathrm{a}$ crença na conjunção-Q: eu tenho duas mãos e, pelo menos, um dos procedimentos que executo para gerar a crença-P não é confiável. ${ }^{1}$ Suponhamos também que $\mathrm{Q}$ seja falsa, mas apenas porque seu segundo conjuncto é falso. ${ }^{2}$ Isso posto, vamos agora supor que $\mathrm{S}$ forma, em $\mathrm{t}_{1}$, a crença verdadeira de que P: eu tenho pelo menos uma mão. Por fim, vamos supor que o procedimento inferencial que gerou a crença-P seja, além de formalmente adequado, confiável e não-anômalo.

1 Considerando que só o segundo conjuncto da proposição-Q tem conteúdo que chamaríamos de 'metaincoerente', o Caso-11 nos permite provar que uma crença pode ser metaincoerente sem que sua proposiçãoobjeto seja constituída apenas de proposições de conteúdo metaincoerente. Além disso, o conteúdo metaincoerente da crença- $\mathrm{Q}$ apresentaria, segundo Klein, outra particularidade importante. Segundo ele, proposições desse tipo poderiam ser utilizadas num argumento cético que faria uso de um princípio que ele chama de 'princípio de eliminação de todas as dúvidas'. Segundo Klein, a principal diferença entre o princípio de eliminação de todas as dúvidas e o princípio de fechamento é que o primeiro, ao contrário do segundo, não lida apenas com proposições logicamente incompatíveis àquelas que são objeto da crença-alvo do agente (ver Skepticism, p. 341).

2 É importante ver que, se o Caso-11 passasse a supor que o segundo conjuncto da proposição-Q fosse verdadeiro, e nós mantivéssemos nossa atribuição de injustificação à crençaalvo, então nossas propostas também permitiriam um resultado que corresponderia a essa atribuição. Afinal de contas, elas nos permitiriam explicar a injustificação da crençaalvo através da cláusula da confiabilidade e da cláusula da necessidade da justificação da crença-premissa para a justificação da crença-alvo. Mas, se ele fosse omisso em relação à verdade/falsidade do segundo conjuncto da proposição-Q, e continuássemos atribuindo injustificação à crença-alvo do caso, alguém poderia alegar que nossas propostas não produziriam resultado que corresponderia as nossas atribuições. O objetor conclui que o Caso-11, que fosse omisso em relação à verdade/falsidade do segundo conjuncto da proposição-Q, constituiria contraexemplo as nossas propostas. Acerca dessa objeção diremos o seguinte: de fato, permaneceríamos atribuindo injustificação à crença-alvo de um Caso-11 que fosse omisso em relação à verdade/falsidade do segundo conjuncto da crença-Q. Mas, isso estaria longe de tornar o caso um contraexemplo às nossas propostas. Isso poderia mostrar, no máximo, que, por ocasião de nosso contato com o caso, atribuímos presumidamente verdade/falsidade àquele conjuncto. Mas, se fosse assim, ou seja, se nossa atribuição de injustificação àquela crença-alvo se devesse a atribuições presumidas feitas quando contactamos o caso, aí mesmo é que versão omissa do Caso-11 não poderia ser usada numa tentativa de refutar nossas propostas. Afinal, se o caso fosse usado para provar que um conceito postulado por nossas propostas como necessário à justificação doxástica não fosse realmente necessário, então o caso usado nessa prova teria que ser de justificação, não de injustificação. Em segundo lugar, o caso teria que veicular as negações dos conceitos que nossas propostas postulam como sendo necessários à análise desse conceito. Mas, o Caso-11 não é explícito em relação a esse assunto. Além disso, se o caso fosse usado para provar que nossa proposta seria insuficiente para justificação doxástica, o Caso-11 teria que veicular suposições que satisfizessem os conceitos postulados por nossas propostas, e não ser omisso sobre esse assunto. E, por fim, se alguém tentasse provar que nossas propostas seriam absurdas, ou seja, que elas implicariam a impossibilidade de uma crença estar justificada, o Caso-11 teria que veicular suposições cujo predicado correspondesse aos conceitos que nossas propostas exigem como sendo necessários à justificação doxástica. 
Ora, diante do caso acima, nós atribuímos injustificação à crença-alvo em questão. Sendo assim, nossa tarefa consiste em mostrar que nossas propostas permitem uma explicação que corresponda a essa nossa atribuição. Nossa estratégia é mostrar que $\pi$ não pode compatibilizar todas as propriedades exigidas por nossas propostas e, sendo assim, $\pi$ constituiria o injustificador da crença-Q, o que, segundo nossas propostas, determinaria a injustificação da crença-alvo do Caso-11, resultado tal que corresponderia as nossas atribuições em relação ao caso.

Para mostrarmos que $\pi$ é um injustificador da crença- $Q$ porque não pode compatibilizar todos os atributos exigidos por nossas propostas, começaremos observando que: ou (1) $\pi$ é inferencial, ou (2) $\pi$ é nãoinferencial. Se $\pi$ é inferencial, $\pi$ pode ser, ou (1a) doxasticamente inferencial, ou (1b) não-doxasticamente inferencial. Sendo assim, e tomando '- ' para 'causa', 'BsQ' para 'S crê que Q' e 'BsP' para 'S crê que P', nós podemos discutir o Caso-11 através das seguintes hipóteses:

Hipótese-(1): $\pi$ (não-inferencial) $-\mathrm{BsO}-\mathrm{BsP}$

Hipótese-(2): $\pi$ (inferencial) - BsQ - BsP

(2a) $\pi$ não-doxasticamente inferencial;

(2b) $\pi$ doxasticamente inferencial.

Vamos começar examinando as implicações da Hipótese-(1). Assim, se $\pi$ fosse um procedimento não-inferencial de geração de crença, $\pi$ teria, segundo (CNIFA), que gerar uma crença que de algum modo reproduzisse as atribuições que o agente efetuou ao executar $\pi$. Nesse caso, para que $\pi$ fosse formalmente adequado à crença- $Q, \pi$ não poderia gerar outra crença que não a crença-Q. Além disso, para que $\pi$ não fosse anômalo, ele teria que gerar mais vezes a crença- $\mathrm{Q}$ do qualquer outra. Ora, dado que $\mathrm{Q}$ é falsa, $\pi$ não poderia ser confiável. Ou seja, se $\pi$ fosse não-inferencial e gerasse de modo formalmente adequado a crença- $\mathrm{Q}$, então, para não ser anômalo, $\pi$ não poderia ser confiável. Ora, é claro que, se $\pi$ não fosse confiável, o segundo conjuncto da crença-O seria verdadeiro, já que ele afirma que, pelo menos, um dos procedimentos de geração da crença-P não é confiável. Uma vez que o Caso-11 assume que esse segundo conjuncto é falso, $\pi$ não poderia compatibilizar as propriedades exigidas por nossas propostas, a não ser que ele fosse um procedimento inferencial. Essa conclusão nos remete diretamente ao exame da Hipótese-(2).

Nosso exame da Hipótese-(2) começará examinando, mais especificamente, a sub-hipótese-(2a). Nós iremos mostrar, em relação a essa sub-hipótese, que, se $\pi$ fosse não-doxasticamente inferencial, a crença- $\mathrm{Q}$ 
não lhe poderia ser formalmente adequada. Para tanto, partiremos da seguinte pergunta: qual seria o procedimento não-doxasticamente inferencial que, do ponto de vista da adequação formal, seria o mais próximo possível da crença-Q? Nós acreditamos que a resposta recaia exclusivamente sobre a suposição de que Q. ${ }^{3}$ Mas, se essa resposta é verdadeira, veremos que o procedimento em jogo não é nem seria capaz de gerar de modo formalmente adequado a crença de $\mathrm{S}$ de que $\mathrm{Q}$. Isso porque a suposição de $\mathrm{S}$ de que $\mathrm{Q}$ só lhe permite gerar de maneira formalmente adequada a crença de $\mathrm{S}$ de que $(\mathrm{Q} \rightarrow \mathrm{Q})$. Ora, mas, se a suposição de $S$ de que $\mathrm{Q}$ não gera de modo formalmente adequado a crença- $Q$, embora essa suposição, presumivelmente, trate-se do procedimento não-doxasticamente inferencial mais próximo da crença- $\mathrm{Q}$ do ponto de vista da adequação formal, então parece-nos certo que não obteríamos um resultado melhor, se estivéssemos lidando com suposições diferentes. Sendo assim, estamos aptos a concluir que, se $\pi$ fosse nãodoxasticamente inferencial, e gerasse a crença- $Q$, então $\pi$ não teria gerado uma crença que lhe fosse formalmente adequada.

Por fim, vamos examinar a sub-hipótese-(2b) da Hipótese-(2). Segundo essa hipótese, $\pi$ seria uma crença. Ora, se $\pi$ tivesse sido uma crença, então, de acordo com as propostas que temos aqui defendido, $\pi$ não apenas tornaria a crença-Q injustificada, mas faria com que sua injustificação

3 Nós não vemos outra opção aqui. Contudo, alguém poderia alegar que haveria um procedimento, de tipo dedutivo, diria o objetor, o qual seria capaz de responder à pergunta acima. Porém, o objetor não estaria se referindo aqui às inferências do tipo crença-paracrença em que o argumento inscrito nessas inferências é de tipo dedutivo. Ele estaria se referindo, por exemplo, ao fato de $S$ deduzir a proposição $Q$ da conjunção (A \& B... \& N). Mas, seria esse tipo de procedimento capaz de gerar justificadamente a crença de que $Q$ ? Nós pensamos que não. Afinal, mesmo que, por hipótese, S pudesse deduzir $\mathrm{Q}$ de $(\mathrm{A} \& \mathrm{~B} \ldots$ \& \& $\mathrm{N}$ ) sem ter acreditado ou suposto a conjunção (A \& B...\& $\mathrm{N}$ ), tal dedução seria inútil aos propósitos do nosso objetor. Afinal de contas, se $\mathrm{S}$ deduzisse $\mathrm{Q}$ de $(\mathrm{A} \& \mathrm{~B} \ldots$ \& $\mathrm{N}), \mathrm{S}$ só poderia crer de modo formalmente adequado em ((A \& B... $\& N) \rightarrow$ Q). Nesse caso, a objeção se mostrou inócua na tentativa de fazer oposição ao ponto que está em jogo na discussão acima. Na verdade, o tipo de procedimento que designamos com os termos 'dedução' e 'indução' e que incide em expressões tais como 'S deduziu/induziu P de Q' ocorre apenas durante a execução dos procedimentos de crença/suposição pelo agente. Isso implica, entre outras coisas, que a crença-alvo resultante desses casos é sempre causada pela dupla de procedimentos e não apenas pelo procedimento doxástico ou suposicional inicial, bem como implica que a dedução/ indução efetuada pelo agente acontece apenas com procedimentos cujo objeto-padrão é um item proposicional. Além disso, o que torna possível que S proceda a uma dedução/ indução, durante a execução do procedimento doxástico/suposicional inicial, é o fato de que $S$ pode reter a execução daqueles procedimentos no tempo. Vamos imaginar que $S$ suponha/creia que $\mathrm{Q}$ e deduza/induza $\mathrm{P}$ de $\mathrm{Q}$. O que lhe permite realizar essa dedução/ indução, durante a execução do procedimento doxástico ou suposicional inicial, é que $S$ pode estender temporalmente a execução daqueles procedimentos iniciais, enquanto realiza, quase-concomitantemente, a dedução/indução da proposição de que $\mathrm{P}$ a partir da proposição de que $\mathrm{Q}$. 
chegasse à crença-alvo. Afinal de contas, para que $\pi$ transmitisse justificação à crença-Q, esse procedimento doxástico teria que ter sido causado por outro procedimento o qual teria que justificá-lo ou transmitir-lhe justificação. Considerando que esse não teria sido o caso, $\pi$ seria, portanto, o injustificador da crença-O. Por fim, cabe notar que, mesmo que alterássemos a hipótese em discussão de modo a adicionar-lhe a suposição de que $\pi$ tivesse sido causado por outro procedimento de $\mathrm{S}$, digamos $\chi$, isso não seria suficiente para tornar possível a justificação da crença que $\pi$ representa na hipótese em jogo. Isso porque, conforme o que estamos propondo nesse ensaio, $\pi$ teria que resultar, no fim das contas, de um procedimento que não fosse doxástico. Ora, mas, sendo assim, $\chi$ teria que ser, ou inferencial, ou nãodoxasticamente inferencial. Ou seja, a emenda em jogo teria como consequência apenas fazernos voltar à discussão da Hipótese-(1) e da sub-hipótese-(2a) da Hipótese-(2), obtendo obviamente os mesmo resultados que obtivemos quando discutimos essas hipóteses há pouco. Ou seja, a emenda seria inútil no sentido de produzir alguma objeção relevante. Sendo assim, podemos terminar o exame da sub-hipótese em jogo e concluir, de acordo com nossas propostas, que, se $\pi$ fosse doxasticamente inferencial e gerasse a crença- $\mathrm{O}, \pi$ geraria uma crença injustificada que transmitiria sua injustificação à crença-alvo do Caso-11.

Assim, o exame que realizamos acima na Hipótese-(1) e na Hipótese-(2) acerca do Caso-11, permite-nos a conclusão de que nossas propostas explicam a injustificação que atribuímos à crença-alvo daquele caso. Deve ser evidente, porém, que não queremos que elas expliquem apenas a injustificação da crença-alvo desse caso particular de metaincoerência ativa na geração da crença-alvo. Em resumo, nós tentaremos mostrar através de nossas propostas que as crenças-alvo dos casos de crença metaincoerente ativa na geração da crença-alvo são casos de injustificação doxástica, simplesmente, porque crenças metaincoerentes sempre serão injustificadas, quer elas tenham sido geradas por outros procedimentos, quer não tenham sido geradas por outros procedimentos. Nesse caso, quer uma crença metaincoerente gere diretamente a crença-alvo, quer a gere indiretamente, a crença-alvo irá receber, invariavelmente, a injustificação dessa crença metaincoerente.

Vamos então ao próximo caso de metaincoerência ativa frente ao qual testaremos as nossas propostas:

Caso-12: Suponhamos que $\pi$ gera, em $t_{1}$, a crença de $S$ na conjunção de que R: eu tenho duas mãos e a maioria dos procedimentos de geração de crença por mim executados é inconfiável. Suponhamos que, em $t_{2}$, e a partir da crença-R, $\mathrm{S}$ forma a crença 
na conjunção Q: eu tenho duas mãos e a próxima crença que eu tiver será resultado de um procedimento inconfiável de geração doxástica. Vamos supor também que, em $t_{3}$, e a partir da crença-Q, S forma a crença verdadeira de que P: eu tenho pelo menos uma mão. Por fim, vamos supor que a maioria dos procedimentos de geração doxástica executados por S seja de fato inconfiável, mas que $\pi$ e o procedimento inferencial gerador de sua crença-P sejam ambos confiáveis, não-anômalos e formalmente adequados.

Como podemos ver, estamos diante de mais um caso cuja crença-alvo está injustificada. Nossa tarefa, então, será determinar se as propostas que temos defendido aqui nos permitem explicar essa injustificação. Mas, antes, será importante fazermos algumas considerações preliminares sobre o caso. A primeira é a respeito do sentido de 'maioria'. É que, se o agente inclui algum dos procedimentos que ele emprega na cadeia de geração de suas crenças-P ao crer que a maioria dos procedimentos de geração de crença por ele executados é inconfiável, o tratamento a ser dispensado ao Caso-12 não irá diferir, em essência, do tratamento que dispensamos ao Caso-11. Considerando que pretendemos testar as nossas propostas frente a casos os mais rigorosos que conseguirmos encontrar, vamos fazer um recorte no sentido do 'maioria' para que ele exclua os procedimentos participantes da cadeia de geração de suas crenças-P. Nesse caso, a crença-R do Caso-12 ficaria da seguinte maneira: eu tenho duas mãos e a maioria dos procedimentos de geração de crença por mim executados, sem contar os procedimentos que participam da geração das minhas crenças- $P$, é inconfiável. E, sendo assim, a crença-Q passa a ser a única crença metaincoerente do Caso-12. A segunda consideração envolvendo o Caso-12 é sobre se $\pi$ poderia gerar justificadamente a crença-R, sendo $\pi$ um procedimento não-inferencial. Nós pensamos que sim, que $\pi$ poderia ser não-inferencial e mesmo assim gerar justificadamente a crença-R. Isso, é claro, não quer dizer que $\pi$ teria que ser perceptual. ${ }^{4}$ Nesse caso, pensamos que $\pi$ poderia

4 Nós assumimos que é impossível que $\pi$ gere justificadamente a crença-R, caso $\pi$ seja perceptual. Mas, nós não o fazemos pelas razões que Dretske sugere em Is Knowledge Closed under Known Entailment?, p. 22. É que Drestke sugere que seria impossível a um procedimento perceptual causar uma crença cuja proposiçãoobjeto versasse sobre confiabilidade/inconfiabilidade de um procedimento de geração de crença. Mas, parecenos perfeitamente concebível uma situação em que um agente creria que certo procedimento de geração de crença fosse confiável porque ele vira, por exemplo, uma nuvem a qual ele atribui ter o formato de uma ovelha. Mas, é claro, isso não nos compromete com a tese de que uma crença assim gerada poderia estar justificada. Em rigor, é isso que tentaremos mostrar que não é possível. 
corresponder a algum procedimento mnemônico de S. Para sermos mais específicos, $\pi$ corresponderia ao fato de $\mathrm{S}$ lembrar-se de ter duas mãos e de ser inconfiável a maioria dos procedimentos de geração de crença que $\mathrm{S}$ executa. ${ }^{5}$

Findadas as considerações preliminares, retomemos nosso principal objetivo em relação ao Caso-12: explicar a injustificação de sua crençaalvo exclusivamente através das propostas que temos defendido nesse ensaio. Nossa estratégia será mostrar que a crença-R gera uma crença que lhe é formalmente inadequada. Se conseguirmos fazer isso, teremos mostrado que a crença- $\mathrm{O}$ está injustificada e transmite sua injustificação à crença-alvo do caso. Para vermos porque a crença-R e a crença-Q não são formalmente adequadas entre si, precisamos considerar que a crença- $R$ é a crença de $\mathrm{S}$ de que ele tem duas mãos e a maioria dos procedimentos de geração de crença que executa, descontando os procedimentos da cadeia de geração das crenças- $P$, é inconfiável. A crença-O de S é a crença de que ele tem duas mãos e a próxima crença que tiver resultará de um procedimento inconfiável de geração doxástica. Nosso ponto aqui é o de que S não poderia inferir adequadamente a crença- $\mathrm{O}$ a partir da crença-R. O que o impediria de fazê-lo? A especificação no sentido do termo 'maioria' expresso na sentença que veicula sua crença-R. Para entendermos melhor o ponto, consideremos o seguinte exemplo: se S acredita justificadamente que a maioria dos homens é mortal, ele pode, a partir disso, inferir de modo formalmente adequado a crença de que o próximo homem também é mortal. ${ }^{6}$ Mas, se ele crê justificadamente que a maioria dos homens chineses é mortal, ele não pode a partir disso inferir de modo formalmente adequado a crença de que o próximo homem, independente de ser chinês ou não, é mortal. Ele só poderia fazê-lo, se a maioria dos procedimentos a que se refere a crença- $R$ incluísse os procedimentos presentes nas cadeias de geração de suas crenças em P. Mas, tal como vimos, isso apenas faria com que a resolução do Caso-12 se tornasse essencialmente a mesma do Caso-11. Sendo assim, a inferência da crença- $\mathrm{Q}$ a partir da crença-R transgride a condição de adequação formal estabelecida em (JDDI), o que

5 Alguém poderia agora perguntar-se sobre como o agente seria capaz de dispor daquele conteúdo mnemônico relativo à inconfiabilidade dos procedimentos de geração de crença. Em resposta, diríamos que o agente poderia recuperálos a partir de registros mnemônicos sobre o tema, tais como, registros testemunhais que o agente dispõe a respeito do assunto ou registros de que ele próprio já acreditara nisso em outras ocasiões, etc.

6 Nós consideramos que o tipo de inferência em jogo acima é formalmente adequado, a despeito de reconhecermos que alguma formulação do Paradoxo da Loteria o envolva (para uma breve introdução a esse e a outros importantes paradoxos chamados 'epistêmicos', ver Kvanvig no verbete correspondente da Routledge Encyclopedia of Philosophy). 
nos permite dizer que (JDDI) fornece uma explicação da injustificação da crença-p do Caso-12.

O próximo casoteste é:

Caso-13: Suponhamos que, em $t_{1}$ e através de $\pi, S$ forma a crença justificada de que P: eu tenho cinco dedos na mão esquerda. Também vamos imaginar que, em $t_{2}$, motivado por um procedimento qualquer de geração doxástica, $\mathrm{S}$ forme a crença de que $\mathrm{Q}$ : nenhum procedimento de geração de crença que eu tenha executado, execute ou venha executar é confiável. Vamos supor agora que, em $\mathrm{t}_{3}$, $\mathrm{S}$ decide revisar sua crença de que $\mathrm{P}$. $\mathrm{S}$ o faz de modo reflexivo e submisso também à meta de obter mais crenças verdadeiras do que falsas. Ele reflete intensamente acerca dos prós e contras em relação à verdade da proposiçãoP, incluindo nessa reflexão o conteúdo de sua crença-O. $\mathrm{Em} \mathrm{t}_{4}$, e exclusivamente por conta de sua reflexão, $\mathrm{S}$ ratifica sua crença em P. Por fim, vamos supor que a ratificação reflexiva da crença-P tenha sido realizada de modo confiável, o que torna $\mathrm{Q}$ evidentemente falsa.

A crença-alvo do Caso-13 se trata de uma crença injustificada. Nosso desafio agora é explicar sua injustificação à luz das propostas que temos apresentado aqui. Nossa estratégia será a de mostrar que a crença-alvo do Caso-13 tem uma história comprometedora no que diz respeito à satisfação das exigências expressas naquelas propostas. Para vê-lo, precisaremos desempacotar uma parte da revisão doxástica feita pelo agente do Caso-13. A série de procedimentos que constitui a revisão doxástica do agente do Caso-13 inicia com a execução de um procedimento mnemônico que causa em $\mathrm{S}$ a crença de que ele acreditara numa proposição na qual, de fato, ele já acreditara. ${ }^{7}$ Ou seja, S lembra-se

7 Se o procedimento mnemônico em questão acima é tal que não acessa conteúdos relativos a crenças realmente já havidas pelo agente, então o procedimento não poderia fazer parte de uma autêntica revisão doxástica. A propósito de tais revisões, é importante dizer, por exemplo, que elas poderiam ser realizadas tendo em vista à satisfação de diferentes metas a serem detidas pelo agente. O agente do Caso-13 realiza uma revisão do tipo reflexivo-epistêmica, o que significa dizer que ele tem que proceder de modo a atingir duas metas conjuntas: crer em mais verdades do que falsidades e proceder de modo formalmente adequado na consideração dos conteúdos recuperados (a satisfação dessa última meta poderia, eventualmente, ter que incluir uma reflexão acerca de se uma determinada forma de geração doxástica é, ou não, formalmente adequada). Além disso, a revisão doxástica se distingue da pura reflexão epistêmica, entre outras coisas, pelo fato de que a última não é constituída por um procedimento de rememoração doxástica, mas por um procedimento de suposição. 


\section{de já ter acreditado que $\mathrm{P}^{8}$ e tal procedimento lhe causa a crença de que já acreditara que $\mathrm{P}$. Em seguida, o agente procede uma recuperação}

8 O emprego de sentenças, tais como 'S lembrase de ter acreditado em P' e 'S crê que já acreditou que P' poderia sugerir algum compromisso nosso com a tese de que, ao revisar suas crenças, o agente entraria em contato consigo mesmo. Mas, nós não queremos assumir tal compromisso. Sendo assim, ao dizermos que $\mathrm{S}$ recupera mnemonicamente uma crença por ele já havida, vamos fixar compromisso, apenas, com a tese de que $\mathrm{S}$ acessa determinados conteúdos armazenados que lhe permitem crer que ele já acreditara que P. Tais conteúdos não são, é claro, o próprio procedimento doxástico de $\mathrm{S}$, mas conteúdos que os procedimentos também geram ao gerarem suas crenças. Tais conteúdos são armazenados pelo agente e são, em princípio, acessíveis via procedimento mnemônico, procedimento que, por sua vez, pode causar crenças já havidas pelo agente. Para exemplificar o que temos em mente, vamos supor que $\mathrm{S}$ veja algo a que atribui ser uma mesa e que esse procedimento lhe cause a crença de que M: há uma mesa. Agora, vamos supor que, além de ter gerado a crença em $\mathrm{M}$, o procedimento perceptual em questão também tenha causado o armazenamento de um determinado conteúdo que, sendo recuperado mnemonicamente por $\mathrm{S}$, causalhe novamente a crença em M. E o que acabamos de exemplificar com essa hipótese também é o que temos em mente quando acima dissermos que o agente do Caso-13 irá lembrarse de conteúdos relativos à geração das crenças de que $P, Q, R \ldots N$. Ou seja, o fato de um agente terse lembrado de um conteúdo relativo à geração de uma crença que ele, de fato, já tivera significa que ele acessou mnemonicamente um conteúdo cuja causação também foi devida ao procedimento gerador daquela crença. Mas, é claro que as considerações feitas aqui com o objetivo de evitar compromisso com a ideia de autocontato deixam algumas dificuldades em aberto. Afinal de contas, há uma diferença crucial entre S lembrarse de um conteúdo que lhe causaria a crença de que Roma é a capital da Itália e S lembrarse de um conteúdo que lhe causaria a crença de que ele já acreditara que Roma é a capital da Itália. A dificuldade que esses casos nos impõem é de dar uma explicação para o tipo de conteúdo que seja, ao mesmo tempo, acessável mnemonicamente, necessário para a justificação daquelas crenças e nãocomprometido com a ideia do autocontato. Afinal de contas, precisamos de uma explicação, não compromissada com a tese do autocontato, que invoque um tipo de conteúdo que, se fosse acessado mnemonicamente pelo agente, pudesse causar-lhe a crença de que ele já acreditara que Roma é a capital da Itália. Para tanto, queremos apostar na hipótese do registro, ou log, de procedimentos do agente. Nossa hipótese é a seguinte: se quando o agente executa um determinado procedimento, ele gera, entre outras coisas, um registro/índice do procedimento executado, tais registros/índices poderiam ser o tipo de conteúdo armazenado o qual poderia ser acessado mnemonicamente pelo agente para causarlhe crenças justificadas sobre sua história procedimental. É claro, entretanto, que, mesmo que a hipótese do log de procedimentos fosse exitosa em resolver a questão para a qual nós a destinamos, alguém poderia alegar, e o faria corretamente, que essa hipótese, no máximo, prestaria o serviço de descomprometer-nos com a ideia de autocontato na revisão doxástica. Não restaria provado aqui que o autocontato é impossível. Mais ainda: alguém poderia assumir que o autocontato é simplesmente inevitável se, por exemplo, $\mathrm{S}$ crê, em t, que $\mathrm{S}$ crê, em t, que P. Nesse caso, poderíamos fazer um pouco mais do que meramente conseguirmos um modo de nos descomprometer com a ideia do autocontato. Para tanto, vamos considerar o seguinte arrazoado: se $\mathrm{S}$ entra em contato consigo mesmo, ele tem de fazê-lo in totum. Em outras palavras, se S entra em contato com algo que dele podemos subtrair, sem que ele deixe de ser $\mathrm{S}$, então $\mathrm{S}$ não faz qualquer autocontato. Sendo assim, podemos dizer que, mesmo que $\mathrm{S}$ creia, em t, que S crê, em t, que P, S não faz qualquer autocontato nessa metacrença. Afinal de contas, o objeto de contato do agente é a proposição de que ele crê que $\mathrm{P}$ em $\mathrm{t}$, não o fato de que ele crê que $\mathrm{P}$ em $\mathrm{t}$. 
mnemônica dos conteúdos relativos à geração das crenças de que $\mathrm{P}, \mathrm{Q}$, $\mathrm{R} . . . \mathrm{N}^{9}$, considerandoos para efeito de se $\mathrm{P}$ é verdadeira ou falsa. $\mathrm{E}$ tal procedimento mnemônico-reflexivoepistêmico causa, por fim, a ratificação da crença de que $\mathrm{P}$ do respectivo agente.

Agora, depois do desempacotamento de parte da revisão doxástica do agente do Caso-13, tentaremos mostrar que as propostas apresentadas neste ensaio permitem o fornecimento de uma explicação para a injustificação daquela ratificação doxástica. Nosso ponto é, basicamente, o seguinte: mesmo que o procedimento mnemônico-reflexivoepistêmico que ratifica a crença-p seja confiável, ele não é formalmente adequado à crença que gera. Afinal de contas, se o agente do Caso-13 considera os

$\mathrm{E}$ mesmo que fosse verdadeiro que $\mathrm{S}$ acreditasse que $\mathrm{P}$ em $\mathrm{t}$, ou seja, que houvesse o fato de $S$ crer que $P$ em $t$, a crença em questão seria perfeitamente subtraível de $\mathrm{S}$, sem que ele deixasse de ser $\mathrm{S}$ (em outras palavras, $\mathrm{S}$ não deixaria de ser $\mathrm{S}$, caso não acreditasse que $\mathrm{P}$ ). Além disso, mesmo que a proposiçãoobjeto da metacrença de $\mathrm{S}$ fosse verdadeira (ou seja, que de fato $\mathrm{S}$ acreditasse que $\mathrm{P}$ em $\mathrm{t}$ ), isso poderia mostrar, quando muito, que a metacrença e sua crença-objeto teriam uma ocorrência paralela, mas não que, ao tê-las, S estaria fazendo contato consigo mesmo. Até mesmo sentenças da forma 'S procede assimeassim em relação a S', as quais parecem sugerir a ocorrência de autocontato, não expressam realmente esse tipo de ocorrência. $\mathrm{O}$ contato que aquelas sentenças realmente expressam se dá entre o agente e algo que de algum modo lhe pertence, mas que, justamente por isso, não é dele inerentemente constitutivo. Não se trata, portanto, de um autocontato. Para um autor que, aparentemente assume um compromisso com a tese do autocontato, ver Chisholm com sua teoria da evidência direta dos estados subjetivos autoapresentantes em Teoria do Conhecimento, $1^{\text {a }}$ ed., cap. 2 e Theory of Knowledge, 3rd ed., cap. 3.

9 Uma importante observação acerca do procedimento mnemônico acima é de que ele não se trata de um procedimento atomizado, ou seja, não se trata de S lembrar-se de um conteúdo relativo à geração da crença-p, depois lembrarse de um conteúdo relativo à geração da crença- $\mathrm{Q}$ etc. O procedimento mnemônico em jogo tem a capacidade de reter conteúdos recuperados, enquanto acessa os outros armazenados. Além disso, nós também vamos assumir que os procedimentos mnemônico-reflexivos, como o que foi executado pelo agente do Caso-13, também têm a capacidade de considerar e classificar os conteúdos recuperados para efeito de se P é verdadeira ou falsa. Sendo assim, vemos que, se um agente não tivesse a capacidade de executar procedimentos que, embora pudessem ser executados atomicamente, podem ser executados em bloco e, em bloco, gerar a crença-alvo, o agente não poderia conduzir uma revisão doxástica reflexivo-epistêmica. Essa capacidade de proceder em bloco é, inclusive, o que nos parece permitir que um agente tenha, entre outras coisas, a crença verdadeira de que ele crê que crê que P. Isso porque, se S crê que crê que $\mathrm{P}$ em bloco com a sua crença de que $P$, então aquela crença de segunda ordem é, tal como vemos, verdadeira. Verdadeira, sim, mas sem incorrigibilidade. Afinal de contas, se o agente não procedesse em bloco àquelas crenças, então a crença de segunda ordem não seria verdadeira. $\mathrm{E}$ mesmo que resolvêssemos assumir que a crença de segunda ordem em questão fosse incorrigível, isso seria insuficiente para tornar a crença de primeira ordem justificada (o que contraria o fundacionismo doxasticista postulado por Chisholm nas diversas edições de seu Theory of Knowledge e Bonjour em Epistemic justification: internalism vs. externalism, foundations vs. virtues). O que torna impossível a justificação da crença de primeira ordem, BsP, via mera ocorrência da respectiva crença de segunda 
conteúdos armazenados $\mathrm{p}^{*}, \mathrm{r}^{*} \ldots \mathrm{n}^{*}$ como sendo pró-verdade de $\mathrm{P}$, então ele tem que considerar o conteúdo $\mathrm{q}^{*}$ como sendo pró-falsidade de que $\mathrm{p}^{*}$, $r^{*} \ldots n^{*}$ sejam pró-verdade de $\mathrm{P}$, ou vice-versa. ${ }^{10}$ Numa situação assim, nós negamos ao agente a condição de poder ratificar, de modo formalmente adequado, a sua crença de que P. Nós diríamos que o conteúdo de que ele dispõe é insuficiente para fazê-lo.

Nesse momento, alguém poderia fazer uma objeção sugerindo uma variação do Caso-13 na qual o agente poderia driblar a inadequação formal presente no caso original. O objetor sugere o seguinte: suponhamos que a recuperação mnemônica dos conteúdos relativos à geração das crenças de que $P, Q, R . . . N$ deixasse de ser reflexivo-epistêmica e passasse apenas a causar a crença de que (P \& $\mathrm{Q} \& \mathrm{R} \ldots$ \& \& N) e, por fim, que essa crença de

ordem, BsBsP, nada tem a ver com a suposta incorrigibilidade dessa última, mas com as exigências de que o justificador cause a crença passível de justificação e que haja uma adequação formal entre o gerador doxástico e a crença-alvo. Ora, uma adequação formal entre BsBsP e BsP só seria possível se ambas ocorressem em bloco e o bloco causasse BsP. Mas, é claro, isso ainda seria insuficiente para justificar BsP, posto que, se o bloco fosse exclusivamente constituído por BsBsP e BsP, ele próprio teria que estar justificado. Como isso seria possível? A resposta que daremos para essa questão está longe de ser definitiva. Contudo, faremos novamente uma aposta sobre procedimentos mnemônicos retentivos. A ideia é então a seguinte: enquanto recupera, e retém, o conteúdo que houvera gerado BsP em seu passado doxástico, o agente também recupera, e retém, o conteúdo que em seu passado doxástico gerara BsBsP (acerca do tipo de conteúdo especificamente envolvido nesse caso, confira a ideia de log de procedimentos do agente). E, agora, parecenos que, se o procedimento mnemônico em questão causasse o bloco (BsBsP-BsP), ele poderia justificálo e, assim, fornecer a condição justificacional para uma ocorrência adicional de BsP. Uma observação final acerca da incorrigibilidade de crenças de segunda ordem sobre crenças de primeira ordem: se crenças de segunda ordem fossem incorrigíveis, isso teria que ser verdadeiro, não somente de outros procedimentos agenciais com a mesma estrutura, mas verdadeiro de qualquer ordem. Mas, isso só pode ser falso. Afinal de contas, se S acreditasse em ordem-5 que $\mathrm{P}$, só para ficarmos com um número baixo, $\mathrm{S}$ também teria que acreditar que $\mathrm{P}$ em ordem-4, em ordem-3, em ordem-2 e, finalmente, em ordem-1. Isso nos parece francamente exagerado.

10 Um agente que se engaja numa revisão doxástica de tipo reflexivo-epistêmica tem, pelo menos, que considerar os conteúdos recuperados mnemonicamente para efeito de se $\mathrm{P}$ é verdadeira ou falsa. Eventualmente, um determinado tipo de agente também teria que considerar o fato de que, se o conteúdo mnemonicamente recuperado envolvendo a crença- $\mathrm{O}$ fosse tomado isoladamente, tal conteúdo tornaria formalmente adequada a crença de que os modos de geração de crença de que um agente dispõe, ou poderia dispor, permitiriam a obtenção de tantas crenças falsas quanto verdadeiras ou mais crenças falsas do que verdadeiras. Nesse caso, ele teria que considerar, tendo sua meta epistêmica em mente, que essa proposição implica que as chances de sua próxima crença ser falsa é, pelo menos, igual à chance dela ser verdadeira. Para um agente com esse grau de sofisticação reflexiva, ou seja, para um agente que considera conteúdos pró-verdade e pró-falsidade de $\mathrm{P}$ e conteúdos relativos à confiabilidade/inconfiabilidade de seus procedimentos de geração doxástica, dada a sua meta de obter mais crenças verdadeiras do que falsas, qualquer crença seria formalmente inadequada, se ele acreditasse em algo como $Q$. 
que (P \& $\mathrm{Q} \& \mathrm{R} . . . \& \mathrm{~N}$ ) causasse a crença-P, com o restante permanecendo o mesmo. Se fosse assim, sustenta o objetor, o agente driblaria a condição de inadequação formal e o faria sem perder a perspectiva de revisão reflexivo-epistêmica, vez que incluiria $Q$ na crença-premissa de sua inferência.

O que dizer sobre a variação sugerida? Podemos começar reclamando que, mesmo se fosse verdade que o agente não estaria incorrendo em alguma inadequação formal nessa variação, isso estaria longe de mostrar, tal como pretende o objetor, que nossas propostas não podem explicar a injustificação da crença-alvo dessa variação. Para vê-lo, basta considerarmos o seguinte: $\left(1^{\circ}\right) \mathrm{Q}$ é falsa, $\left(2^{\circ}\right)$ a reflexão epistêmica sobre se $\mathrm{P}$ é verdadeira ou falsa tem de ser constituída, por força do próprio caso, pela crença de que (P \& $\mathrm{Q} \& \mathrm{R} . . . \& \mathrm{~N})^{11}$ e $\left(3^{\circ}\right) \mathrm{Q}$ não pode faltar nessa "reflexão". ${ }^{12}$ Ora, nesse caso, o procedimento gerador da crença de que (P \& Q \& R... \& N) não teria como ser confiável. Por força do caso, ele não poderia deixar de gerar uma crença que não tivesse $Q$ entre os conteúdos. Dado que Q é falsa, o procedimento mnemônico sugerido nessa variação seria inconfiável e, por conta disso, tornaria injustificada a crençapremissa da inferência que, injustificada, faria também injustificada a crençaconclusão do caso, ou seja, a crença-P.

Chegamos, enfim, ao último caso frente ao qual queremos checar nossas propostas:

Caso-14: Suponhamos que S seja um cérebro na cuba. ${ }^{13}$ Vamos supor agora que, motivado por uma forte crise de culpa, um dos cientistas integrantes do experimento decide contar toda a verdade para S. Para fazê-lo, o cientista usa os mesmos aparelhos de simulação perceptual usados no experimento e declara à cobaia que, com exceção desse evento particular de revelação, tudo aquilo em que ele acreditara antes, via procedimento perceptual de geração doxástica, era sistematicamente falso. Para encerrar a hipótese, vamos imaginar que $\mathrm{S}$ creia no relato do cientista arrependido.

11 É muito claro, para nós, que o fato do agente incluir a proposição-Q na crença-premissa em discussão não faz da respectiva inferência uma revisão reflexivo-epistêmica da crença-P

12 Por força do caso, a proposição-Q tem de ser incluída na crença-premissa da inferência da revisão "reflexiva" do agente. Se ela não fosse incluída, a variação em jogo deixaria até mesmo de ser um caso de metaincoerência ativa na geração da crença-alvo e se tornaria, portanto, irrelevante para a discussão que estamos empreendendo aqui.

13 O Caso-14 se inspira no original de Putnam em Brains in a Vat. 
Agora, ao contrário do modo como procedemos nos casos anteriores, nós não atribuímos injustificação à crença-alvo do Caso-14, que, é importante observar, não se trata de um caso de metaincoerência. Curiosamente, nós também não atribuímos justificação à crença em questão. Sendo assim, o Caso-14 se enquadra naqueles casos em que, dada a falta de suposições relevantes, nós nos abstemos de atribuir tanto o conceito de justificação, quanto o de injustificação. É claro que, dada a omissão de determinadas suposições relevantes para atribuição de algum desses conceitos, nós poderíamos ter atribuído, de modo presumido, conceitos que seriam veiculados em tais suposições. Nesse caso, nós não teríamos nos refreado de atribuir um ou outro daqueles conceitos. Mas, não foi isso que aconteceu. Seria o Caso-14 irrelevante para os propósitos analíticos deste ensaio? Em absoluto, afinal de contas, ele nos mostra que, se considerarmos apenas as suposições explicitamente expressas no caso, podemos concluir que não há qualquer impedimento para a possibilidade de justificação da crença-alvo, o que, eventualmente, poderia implicar que também não há qualquer impedimento para a possibilidade de $\mathrm{S}$ saber a respectiva proposição-alvo do caso, ou seja, a de que ele tem sido, até ali, vítima de cientistas manipuladores. ${ }^{14}$ Sendo assim, a questão que, parecenos, tornou-se pertinente é a de se as nossas propostas permitem concluir que o agente acima poderia estar justificado e, eventualmente, saber que foi vítima de cruéis cientistas. Sim, nós pensamos que as propostas aqui defendidas não bloqueiam a possibilidade da crença-alvo do Caso-14 ser justificada. Nós arriscamos dizer que, se o Caso-14 recebesse suposições que expressassem a satisfação das exigências feitas em nossas propostas, nós abandonaríamos a abstinência atributiva e passaríamos a atribuir justificação à crença-alvo do Caso-14.

14 Para Nozik, ver Philosophical Explanations, cap. 3, S não pode saber que é verdadeiro, ou falso, que tem sido vítima de cientistas manipuladores, pois, segundo ele, qualquer que fosse o método que conduzisse o agente a crer naquelas proposições, seria incapaz de satisfazer às condições de rastreabilidade da verdade. Embora consideremos que as condições de rastreabilidade não sejam verdadeiras, não sem qualificações adicionais, nós não discutiremos essas condições aqui. De qualquer modo, mesmo que, por hipótese, Nozick estivesse certo em negar conhecimento à crença-alvo do agente do Caso-14, parece-nos que nós poderíamos insistir na tese de que aquela crença poderia ser, pelo menos, justificada. Sim, embora consideremos que a proposição-alvo do Caso-14 não seja impedida de ser conhecida, ela poderia pertencer a alguma classe de proposições que podem ser objeto de crença justificada, mas não podem ser objeto de conhecimento. É o que pensamos que acontece, por exemplo, com as chamadas "proposições lotéricas" (confira, nesse sentido, o tratamento dado por Lewis em Elusive Knowledge ao Paradoxo da Loteria e ao Problema de Gettier através da regra da similaridade). 


\section{Considerações finais}

No decorrer desse ensaio, vimos que a injustificação de uma crença causada por uma crença metaincoerente pode ser explicada por uma proposta de justificação doxástica de concepção confiabilista. Considerando que ela explica tal possibilidade sem fazer uso de nenhuma cláusula do tipo antisolapamento da justificação, podemos concluir, a partir de agora, que dispomos de uma proposta de concepção confiabilista que esteja, de fato, imune à objeção da metacoerência.

\section{Apêndice}

A tese de que o método hipotético-dedutivo não começa, nem termina, com uma crença enfrenta algumas dificuldades as quais gostaríamos de relatar. Para facilitar a captura do nosso ponto, vamos retomar a caracterização já iniciada antes para esse tipo de método. Nós já dissemos que o método hipotético-dedutivo é constituído por uma sequência de procedimentos que um agente executa para resolver um determinado problema de ordem intelectual e que esse problema pode ser expresso na forma de uma pergunta. O início da execução do método hipotético-dedutivo é quando o agente propõe uma resposta - a hipótese - à pergunta que expressa o problema. Essa resposta - ou aquilo que se deduz dela, ou com ela - é submetida ao teste observacional que, se levado a termo, permite que o agente decida se sua hipótese responde verdadeiramente àquela pergunta, e, nesse caso, diríamos que o teste confirma, em algum grau, sua hipótese - ou se sua hipótese responde falsamente àquela pergunta - e, nesse caso, diríamos que o teste desconfirma sua hipótese.

Sendo assim, parecenos que não teremos dificuldade em mostrar que é impossível a um usuário do método hipotético-dedutivo iniciar sua execução sem que seja exclusivamente através de uma crença. Isso porque, se um agente assume a meta de responder verdadeiramente a uma pergunta que expressa um problema intelectual qualquer e propõe uma resposta para fazê-lo, esse agente assume um compromisso de algum grau com a verdade de que aquilo que ele propôs como resposta responde verdadeiramente a respectiva pergunta. Mas, não só. Pois, se o agente assume um compromisso de algum grau com a verdade de que aquilo que ele propôs como resposta responde verdadeiramente à pergunta em jogo, então ele também assume um compromisso de algum grau com a verdade da proposição que é objeto de sua resposta. E se o agente assume um compromisso de algum grau com a verdade da proposição que é objeto de sua resposta, que no método hipotético-dedutivo chamamos 
de 'hipótese', o agente assume um tipo de compromisso que é, para nós, marca indelével e suficiente da crença.

$\mathrm{E}$ se o que acabamos de dizer é verdade, então a formulação de uma hipótese não pode, sob pena de inadequação formal numa eventual geração doxástica, ter o grau de liberdade que alguns nos parecem sugerir que ela tenha. ${ }^{15}$ Não nos parece que um agente, que detém metas vinculadas à obtenção de crença justificada e conhecimento, poderia formular hipóteses que conflitassem com sua base prógeração doxástica. Para vê-lo, vamos supor que Sherlock Holmes estivesse prestes a iniciar uma investigação acerca do assassino de Mister X. O corpo de Mister X foi encontrado na biblioteca da mansão enquanto transcorria o baile de máscaras que ele oferecia anualmente para restritos cem convidados. Suponhamos que Holmes acredite em tudo isso que acabamos de mencionar e, mais, que o assassino está entre os cem convidados. Poderia Holmes partir justificadamente de qualquer hipótese? Não. Afinal de contas, Holmes não teria a liberdade de partir, por exemplo, da hipótese de que o assassino fora o Mago Merlin, se Holmes tivesse base para crer que o bom Mago não estivesse entre os participantes do baile. Ou seja, se Holmes assumisse a hipótese de que o Mago Merlin fora o assassino, desconsiderando, assim, sua base para crer que o bom Mago não figurava entre os convidados, nós diríamos que Holmes estaria procedendo irracionalmente ao assumir aquela hipótese. Mas, as dificuldades para a tese da total liberdade na formulação de hipóteses não param por aí. Para vêlas, suponhamos agora que Holmes tivesse formado, previamente, a crença de que, entre os convidados do baile, há candidatos mais prováveis ao crime do que outros. Para simplificarmos ainda mais, vamos supor que Holmes tivesse base para isolar apenas dois indivíduos como os mais prováveis assassinos: o mordomo e Mister Y. Nesse caso, parecenos que também seria irracional que Holmes assumisse a hipótese de que o criminoso teria sido um terceiro convidado: Mister Z. Ou seja, a inicialização do método hipotético-dedutivo é doxástica e não pode ter, sob pena de injustificação e ignorância, um grau de liberdade que permita a formulação de uma hipótese que seria formalmente inadequada em relação à base prógeração doxática desse agente.

Mas, a tese de que o método hipotético-dedutivo começa com uma crença ainda está sujeita a algumas objeções sérias. Uma delas seria a de que, se um agente estivesse convicto da verdade da resposta que ele

15 Confira a doutrina do anarquismo epistemológico de Feyerabend em Knowledge, Science and Relativism. Se o valetudo metodológico fosse levado às últimas consequências, o agente poderia formular, sem ônus epistemológico, hipóteses que fossem formalmente incorretas em relação à base próinferência que esse agente possui. Nós temos tentado mostrar aqui que isso é falso. 
dá ao problema intelectual que pretendera resolver, então também seria irracional que ele submetesse sua resposta a teste, qualquer que fosse ele. Nós concordamos com essa objeção. Se Holmes tivesse a convicção de que o assassino fora o mordomo e encaminhasse qualquer teste dessa sua convicção, esse teste seria irracional. É claro, essa nossa atribuição de irracionalidade a Holmes está vinculada ao fato de termos feito uma série de atribuições presumidas acerca do tipo de agente que Holmes é e acerca das metas que ele possui. Por exemplo, nós presumimos que Holmes possui, entre outras metas, a de responder verdadeiramente às perguntas a que se propõe responder e de fazê-lo de um modo que ele crê não ser supérfluo, ou desnecessário, do ponto de vista de sua pretensão de uso. Ora, esse é justamente o ponto que faria com que Holmes procedesse irracionalmente, caso ele submetesse uma sua convicção a teste. Afinal de contas, a execução do teste observacional é para decidir a respeito da verdade/falsidade de sua resposta (hipótese). Isso, porém, Holmes já teria feito, justamente em função de sua convicção de que o mordomo seria o culpado. Atento a tais observações, nosso objetor poderia apresentar uma solução à irracionalidade do teste de convicções, ainda no interior de sua perspectiva antidoxástica na inicialização do método hipotético-dedutivo. Ele diria que Holmes evitaria todas as possíveis irracionalidades envolvendo a execução do método hipotético-dedutivo, se ele principiasse a execução desse método, não com uma crença, mas com uma dúvida. É claro, diria o objetor, não seria dúvida acerca de quem matou Mister X, uma vez que essa é a dúvida vinculada à pergunta de ordem, mas dúvida acerca de se um determinado indivíduo é, ou não, o autor do assassinato. Ora, a sugestão, bem intencionada de nosso objetor, de que a dúvida seria o procedimento inicializador do método hipotéticodedutivo não tem a mínima chance de prosperar. Afinal de contas, nós já vimos que: se S propõe ' $P$ ' para responder verdadeiramente a uma dada pergunta, $\mathrm{S}$ assume um compromisso com a verdade da resposta que propõe. Nesse caso, como poderia o agente ter dúvida sobre a verdade de P? Não poderia.

Isso posto, alguém poderia sugerir que estamos diante de um dilema insolúvel. Ou seja, se Holmes, tal como o caracterizamos, está prestes a inicializar o método hipotético-dedutivo e, em razão disso, propõe uma resposta à pergunta acerca de quem matou Mister X, então Holmes toma sua resposta como verdadeira. Mas, se ele está convicto da verdade de sua resposta, ele não pode submeter racionalmente essa resposta a teste e, portanto, não pode executar o método em questão. Para não estar convicto da verdade de sua resposta, Holmes teria que partir de uma dúvida relativa à autoria daquele assassinato. Mas, conforme já vimos, ele jamais poderia partir de uma dúvida acerca do assunto, uma vez que 
teria que crer no conteúdo da resposta que propõe. Seria o dilema de Holmes insolúvel? Certamente que não. Tratase de um falso dilema, e o ponto exato de sua falsidade tem a ver com o fato de que crenças vêm em graus. A convicção é apenas um dos graus da escala de intensidade da crença - o quasemáximo. Sendo assim, nós arriscamos dizer que Holmes não cometeria qualquer irracionalidade, se principiasse a execução do método hipotético-dedutivo com uma crença cuja intensidade fosse adequadamente baixa. Esse tipo de crença, que costumamos chamar de 'suspeita' ou 'desconfiança', permitiria que o agente empregasse, sem irracionalidade envolvida, o teste observacional para aumentar o grau de sua crença, caso ele a confirmasse naquele teste, ou zerar completamente aquele grau, caso ele a desconfirmasse. Em resumo, se o agente inicializa o método hipotético-dedutivo com uma crença cujo grau de adesão é adequadamente baixo, então, primeiro, ele não procederá irracionalmente ao submeter sua hipótese (ou o que se deduz dela ou com ela) ao teste observacional e, segundo, a real função do teste observacional, no emprego do pacote de procedimentos que constitui o método hipotético-dedutivo, é de promover uma alteração na intensidade da crença de partida do agente.

As considerações acima nos perecem resolver algumas das perplexidades envolvendo a questão da racionalidade geral do usuário do método hipotético-dedutivo. Resta, entretanto, uma importante questão em relação a qual faremos algumas breves considerações e que versa sobre o status justificacional da suspeita/desconfiança com a qual o agente principia a execução do método hipotético-dedutivo. A questão é a seguinte: considerando que a crença com a qual um agente inicializa o método hipotético-dedutivo se trata de uma crença de baixa intensidade - uma suspeita ou desconfiança - poderia a crença em jogo ser justificada? Para divisarmos melhor as dificuldades envolvidas nessa questão, retomemos uma vez mais o caso da investigação de Sherlock Holmes sobre o crime de Mister X. Vamos supor que Holmes tivesse isolado dois indivíduos para serem os mais prováveis candidatos ao crime - o mordomo e Mister Y - e que Holmes, tal como nas situações lotéricas, não tivesse base para suspeitar de um mais do que do outro. Em tal situação, se Holmes suspeitasse de algum deles em particular, nós diríamos que sua suspeita seria injustificada, uma vez que a crençapremissa que Holmes possui em relação ao caso não permitiria que a inferência em jogo fosse formalmente adequada.

Nesse momento, alguém poderia alegar que a situação em que pusemos Holmes tratase da situaçãopadrão de aplicação do método hipotético-dedutivo. Argumentaria o objetor que o método hipotéticodedutivo é um método de descoberta e que, em tais métodos, o agente 
parte necessariamente de crença injustificada para chegar a uma crença justificada. Em resposta, diremos que é falso que métodos de descoberta tenham necessariamente tal propriedade (aliás, se eles a tivessem, o objetor estaria comprometido com a absurda tese de que métodos de descoberta e conhecimento seriam incompatíveis). Mas, Holmes, e outros agentes, podem ficar tranquilos, porque podem compatibilizar perfeitamente suas metas gnosiológicas com o uso de métodos de descoberta. A solução é a seguinte: dado que Holmes não tem base para suspeitar mais do mordomo do que Mister Y, e vice-versa, ele deve, pura e simplesmente, abandonar o emprego do método hipotético-dedutivo. $\mathrm{Na}$ situação em que se encontra, Holmes pode apenas ficar em dúvida sobre a autoria individual do crime, abstendo-se, portanto, de suspeitar de qualquer um dos personagens em particular. Sendo assim, Holmes teria que sair em busca de alguma informação adicional que, ou lhe permitisse suspeitar justificadamente de apenas um dos personagens, ou lhe permitisse crer convictamente que um deles em particular é o autor do crime. Ora, em qualquer uma das alternativas que viessem ocorrer, nosso detetive predileto teria abandonado o curso de aplicação do método hipotético-dedutivo, porque teria executado outro método de descoberta.

Mas, resta uma questão ainda aberta sobre o assunto acima. Como Holmes poderia deixar de suspeitar injustificadamente em apenas um daqueles personagens e, nesse caso, inicializar o método hipotéticodedutivo sem qualquer incompatibilidade com sua meta gnosiológica máxima? Para vê-lo, vamos supor que Holmes lembra que, em determinada ocasião, Mister X lhe dissera que ambos, o mordomo e Mister Y, outrora amigos entre si, passaram a mostrar, cada um a seu jeito, estranha e grande animosidade de comportamento em relação a ele. Holmes também lembra que Mister X afirmara, em seu relato, que o mordomo tivera um passado criminoso e que ele, Mister X, concederalhe o emprego após ele fugir da prisão onde cumpria pena por assassinato. Ora, numa tal conjuntura, Holmes poderia suspeitar justificadamente do mordomo e, assim, inicializar o método hipotético-dedutivo sem crença injustificada.

As observações feitas acima deixam, contudo, em aberto uma importante questão: se a suspeita com a qual Holmes iniciasse o método hipotético-dedutivo fosse justificada, porque ele deveria, se deveria, submeter aquela hipótese ao teste observacional? Bem, nós não temos aqui a pretensão de dar uma resposta definitiva para essa questão. De qualquer modo, desconfiamos que a resposta mais adequada para ela seria a seguinte: Holmes só deveria submeter sua hipótese ao teste observacional, se ele detivesse, não apenas a meta de obter crença 
justificada, mas, sobretudo, a meta de ter convicção justificada. Ora, mesmo que disséssemos que a suspeita de Holmes fosse justificada, não diríamos que Holmes saberia a proposição objeto da respectiva suspeita. Isso sugere que assumamos, tal como outros já assumiram ${ }^{16}$, que conhecimento não se trata apenas de crença verdadeira justificada etc., mas de convicção verdadeira justificada etc.

\section{Referências}

ARMSTRONG. D. M. A materialist theory of mind. Londres e Nova York: Routledge. 1968.

BONJOUR, L. Internalism and externalism. In: Paul K. Moser (ed.). The Oxford Handbook of Epistemology: 234-263. Nova York: Oxford University Press, 2002.

. Externalist theories of empirical knowledge. In: S. Bernecker e F. Dretske (edits.). Knowledge: readings in contemporary epistemology: 178-198. Nova York: Oxford University Press, 2000.

BONJOUR, L. e SOSA, E. Epistemic justification: internalism vs. externalism, foundations vs. virtues. Nova York: Blackwell Publishing, 2003.

CHISHOLM, R. Teoria do conhecimento. Rio de Janeiro: Zahar. 1969.

Theory of knowledge. $3^{\text {rd }}$ ed. Nova Jersey: Prentice Hall. 1989.

CONEE, E, e FELDMAN, R. The generality problem for reliabilism. Philosophical Studies 89:1-29. Kluwer Academic Publishers, 1998.

DANCY, J. Epistemologia contemporânea. Lisboa: Edições 70, [s/d.].

DRETSKE, F. Conclusive reasons. The Australasian Journal of Philosophy, n. 49, 1971.

Is knowledge closed under known entailment?. In: M. Steup e E. Sosa (eds.). Contemporary Debates in Epistemology: 14-26. Malden: Blackwell, 2005.

FOLEY, R. What's wrong with reliabilism? In: S. Bernecker e F. Drestke (eds.). Knowledge: readings in contemporary epistemology: 166-177. Nova York: Oxford University Press, 2000 (Reimpressão de "The Monist", 68: 188-202, 1985).

FEYERABEND, P. K. Knowledge, science and relativism. J. Preston (ed.). UK: Cambridge University Press, 1999.

FUMERTON, R. Metaepistemology and skepticism. Rowman and Littlefield Publishers, 1995.

GINET. C. Infinitism is not the solution to the regress problem. In: M. Steup e E. Sosa (edits.), Contemporary Debates in Epistemology: 140-149. Nova York: Blackwell, 2005.

GOLDMAN, A. I. Epistemology and cognition. Cambridge: Harvard University Press, 1986.

16 Confira Klein em Certainty: a Refutation of Skepticism, p. 127-134 e 150. Confira também Wittgenstein em On Certanty, p. 3e, par. 8 e p. 27e, par. 194. 
E.C. Valcarenghi - Confiabilidade, coerência e metaincoerência (continuação e fim)

. Reliabilism. In: Routledge Encyclopedia of Philosophy. CD-ROM, version 1.0. Londres e Nova York: Routledge, 1998. $\overline{5169,} 1988$.

Strong and weak justification. Philosophical Perspectives, 2, Epistemology,

. What is justified belief? In: Empirical Knowledge: readings in contemporary epistemology: 171192. Rowman \& Littlefield. 1986 (Reimpressão de Justification and Knowledge: 1-23. G. S. Pappas ed. Dordrecht: Reidel, 1979).

HARMAN, G.; KULKARNI, S. R. The problem of induction. Philosophy and Phenomenological Research: 559-575, v. LXXII, n. 3, maio 2006.

HUME, D. Investigação sobre o entendimento humano. Artur Morão (trad.). Lisboa: Edições 70, [s/d.].

KLEIN, P. D. Certainty: a refutation of skepticism. University of Minnesota Press: Minneapolis. 1981.

. Is infinitism the solution to the regress problem?. In: M. Steup e E. Sosa (eds.), Contemporary Debates in Epistemology: 141149. Nova York: Blackwell. 2005.

Skepticism. In: P. K. Moser (ed.). The Oxford Handbook of Epistemology. Nova York: Oxford University Press: 336-361, 2002.

. The virtues of inconsistency. Monist, 68:105-145, 1985.

KVANVIG, J. Epistemic paradoxes. In: Routledge Encyclopedia of Philosophy. CDROM, version 1.0, London and New York: Routledge, 1998.

. Two approaches to epistemic defeat. Disponível em: <http://www.missouri. $\overline{\mathrm{edu} /}$ kvanvigj/papers/plantingaondefeat.pdf $>$. Acesso em 30/11/05.

LEWIS, D. Elusive knowledge. In: K. DeRose e T. Warfield (eds.), Skepticism: a contemporary reader. New York: Oxford University Press, 1999. (Reimpressão de Australasian Journal of Philosophy, 74: 549-567. 1996).

NOZICK, R. Philosophical Explanations. 13 ${ }^{\mathrm{a}}$ ed. Cambridge: Harvard University Press, 2000.

POPPER, K. R. Conhecimento objetivo: uma abordagem evolucionária. Milton Amado (trad.). São Paulo: Edusp, 1975.

. The logic of scientific discovery. Londres e Nova York: Routledge, 2002.

PUTNAM, H. Brains in a vat. In: K. DeRose e T. Warfield (eds.), Skepticism: a contemporary reader. New York: Oxford University Press, 1999 (Reimpressão de Reason, Truth and History. Cambridge University Press, 1981)

VALCARENGHI. E. C. Internalismo e crença epistemicamente racional. O que nos faz pensar, n. 25, Dez. 2009. 239-265.

. O confiabilismo de A. I. Goldman e o problema da generalidade. Tese de Doutorado. PUCRS, 2004.

. O internalismo pode integrar uma análise correta do conceito de conhecimento? Kriterion, n. 117, Jun. 2008. 39-66.

. Confiabilismo e metaincoerência. Artigo a ser publicado, 2010.

WITTGENSTEIN, L. On certainty. G. E. M. Anscombe e G. H. von Wright (eds.). D. Paul e G. E. M. Anscombe (trads.). Oxford: Basil Blackwell, 1969. 